\title{
'Good Effort, But Must Try Harder': Civil Society Organisations and Education in Delhi
}

\author{
Araddhya Mehtta
}

\begin{abstract}
1 Introduction
What role have civil society organisations (CSOs) played in improving the access and quality of education for low-income groups in the Indian education system? Questioning the nature of the role played by CSOs - non-governmental organisations (NGOs), grassroots organisations, activist groups of academics and parents - is compelling for two reasons. On the one hand, there is growing evidence that the government has failed to deliver education services; and for-profit private providers and CSOs are filling the gap. This is highlighted by the fact that many poor people send their children to expensive private schools or CSOrun schools, despite the presence of government schools in their neighbourhoods (Kantha and Narain 2005: 61). On the other hand, there appears to be a growing confidence in the ability of civil society to hold the state accountable for the delivery of services. For example, the recent mandatory implementation of the Mid-Day Meal Scheme in India was the result of a prolonged effort on the part of the CSO network - the Right to Food Campaign - to hold the state accountable (Right to Food Campaign 2006). As the influence of CSOs in policy and implementation has grown, it raises the question: does CSO involvement improve quality and access in education?
\end{abstract}

By tracing the role of CSOs in elementary education policy in Delhi, I put forward a simple proposition when CSOs participate in policy formulation, positive outcomes are more likely for two reasons. First, the policies that emerge through CSO involvement are more likely to 'fit' the social and institutional realities on the ground. Second, CSOs themselves are more likely to take on the task of holding the state to account in implementation. At first glance, this seems obvious. Yet recent policy debates have tended to stress the importance of autonomy (from the state) of CSOs that engage in accountability as a key condition for credibility of their work. Collaborating with the state in shaping policy can be seen as cooptation, particularly when CSOs also participate in policy implementation. In contrast, this article will argue that policy embeddedness is essential to CSO success in direct accountability. Participation in policymaking enables CSOs to embed practical roles for themselves in implementing policy and a detailed knowledge of programmes enables them to put societal accountability mechanisms to effective use.

\section{Methodology}

In this article, I trace the involvement of CSOs in the state of Delhi during the past 20 years. Over a period of three months in 2006, I interviewed 30 academics, activists, heads of NGOs and government officials in the field of education in India. The article draws on these interviews and a desk review of literature on this subject to support my proposition. I look at three cases of education policy reforms - the Universal Elementary Education Programme, the Sarva Shiksha Abhiyan (SSA); the SCERT textbook case; and the Mid-Day Meal Scheme. These cases have been chosen here, because they significantly impacted on the access and quality of basic education available to the poor. A case study approach to address this question has been taken for two reasons. First, it is clear that educational outcomes are complex phenomena; 'improved' service delivery in education is not purely measured by 'narrow' indicators, such as higher average marks or greater enrolment. In addition, 'broad' outcomes 
that are less tangible and less easily measured, such as quality, are also important. Second, a case study approach permits more detailed analysis of the quite complex and varied mechanisms through which CSOs improve service delivery. Clearly, more work in this area is required, but these initial studies provide indications of positive outcomes.

The article is organised in the following manner: Section 3 provides a brief background on education policies in India; Section 4 outlines two important challenges facing the Delhi education system; Section 5 lays out the three case studies: Sarva Shiksha Abhiyan, the design of SCERT textbooks, and the Mid-Day Meal Scheme, which demonstrate the interactions between civil society and the government in education, and Section 6 concludes with a summary of the positive outcomes of each case study and reiterates how civil society's practical involvement in the policy process results in better policy design, implementation, and mechanisms of accountability.

\section{Background to education policy in India}

Education in India is guaranteed by the state. The constitution of India adopted in 1950 stipulates that education should be free and compulsory for children up to the age of 14. Two policy initiatives in 1968 and 1986 operationalised this principle. The 1968 National Policy on Education aimed to improve the quality of existing private and public schools - as opposed to opening new schools with privileged access - by integrating private and government schools, including government-aided schools, within the overall education system. Ultimately, the policy was unable to integrate schools and consequently failed to improve access to and the quality of basic education.

In order to achieve the goals of the 1968 policy, the 1986 policy prioritised elementary education and the education of women and girls from marginalised groups, also known as Scheduled Castes and Scheduled Tribes, and used micro-planning, decentralisation and strengthening of non-formal education centres as concrete mechanisms to address concerns of access, quality and utility of education. The 1986 policy launched a slow but steady process of NGO inclusion as advisers for the formation of government policies. An NGO presence was seen as essential for micro-planning and strengthening of non-formal education centres.
Successful implementation has primarily been in rural areas, which had clearly been the focus of the policy. A separate policy focusing on urban education issues has yet to be formulated in detail (Kaushik 2005).

In 1993, the Supreme Court passed a landmark judgement, in which it read the right to education as being a part of Article 45, which safeguards the right to life (Mehendale 2005). This led to the Right to Education Bill that was first introduced in parliament in 1997 by the United Front Government - a coalition of the Janata Dal, the Left and some other smaller parties. Due to political upheaval however, the Bill did not get discussed and was reintroduced by a different government - the Hindu nationalist Bharatiya Janata Party-led National Democratic Alliance, in 2001. In the interim, several NGOs, activists, academics and grassroots networks lobbied to have the Right to Education Bill passed with some amendments (Mehendale 2005). By targeting both high level policymakers and politicians as well as the grassroots players, they were able to highlight the need for education reforms to improve access and quality. $A$ cross party consensus on the importance of passing such a bill was created so that the law was passed without opposition in 2002.

Education is a concurrent subject within the Indian constitution, both the central government and the states have responsibility for formulating policies. The states are responsible for translating central policies into local programmes and policies. Although the $73 r d$ and 74th constitutional amendments further decentralised responsibilities for education from the state to the municipal levels, their application in urban areas has been weak. Urban municipalities have limited management over local education systems as a consequence. In Delhi, a national capital in which state boundaries broadly coincide with urban boundaries, there are greater challenges to the implementation of educational policies that pose difficulties for CSO involvement.

\section{Challenges facing the state of Delhi education system}

In order to understand the complex political and social environment in which CSOs in Delhi work, I will outline two important challenges. First, the presence of multiple authorities responsible for imparting education has made accessibility to educational entitlements difficult for the poor. Each authority follows a separate bureaucratic order, with 
different and difficult rules, regulations, fees and admission procedures. Elementary education consists of four formal systems. Three of these systems are under local bodies: the Municipal Corporation Delhi (MCD), the New Delhi Municipal Corporation (NDMC) and the Delhi Cantonment Board (DCB). The fourth system is the Directorate of Education (DoE) under the State Government Sector and autonomous bodies of the National Capital Territory (NCT) of Delhi (NCT 2007).

Second, the quality and accessibility of education has been poor, especially for children from marginalised groups. In the past, primary education was dominated by government-run schools that were nominally free. Private schools have multiplied in recent years, resulting in increasingly expensive education in India. Since the late 1980s, with liberalisation of the economy and a reduction of controls over the opening of new educational institutions, there has been a mushrooming of private schools catering to all income levels (Sinha 2005). ${ }^{1}$ Most urban cities have private brand-name schools that charge high fees (Kantha and Narain 2005). In Delhi, government-aided schools, which originally intended to educate the urban lower and middle classes, have shifted their pupil base towards richer students (Kantha and Narain 2005). The government reproduces stratified education through restricted-entry schools, such as the Kendriya Vidyalayas and Sainik schools, which cater exclusively to the needs of government and army personnel. The limited number of schools for high achievers, called Navodaya Vidyalayas, further adds to the competition and stratification of Delhi government schools. Special ability government schools, like Sarvodaya and Navyug schools are also in high demand. All these exclusive government schools have better infrastructure and facilities and a more balanced student-teacher ratio. Narain (2005) argues that the presence of a limited number of wellendowed government schools has created exclusive and expensive education. At the same time, a number of private, non-aided schools have opened up, aimed specifically at low-income groups (Tooley and Dixon 2005). However, these schools are characterised by relatively high fees, lack of infrastructure, lack of transparency in finances and poor teaching. Although these private schools provide a previously underserved group with access to education, quality remains a major issue. Many private schools are profit-driven commercial enterprises that prey on the vulnerability of the poor, who will pay for private education in English over a perceived low-quality education in Hindi provided by government schools.

In a context in which education is viewed as a route out of poverty, the poor struggle between complex and exclusionary government-provided education and expensive private education. A poor-quality education, whether costly or free, is often the poor's only option.

CSOs are actively tackling these challenges. In Delhi, the multiplicity of public authorities responsible for education and the proliferation of private schools make the implementation of a uniform education policy difficult. Though the presence of the NGOs has not simplified the complex education structure, they have reduced the gap between the citizens and government in the course of their involvement in policy formulation and implementation. And while the level of civil society involvement in different localities and issues varies, in the places where they have been active they have created multiple avenues through which a larger number of people can demand rights and become active actors in delivering and monitoring services.

\section{Case studies of reforms in education}

CSO involvement in education policy formation in India is relatively recent. While CSOs have always run some schools themselves, these have now grown in number. Further, CSOs are now taking an interest in educational policy formation as well as regulation of private schools, an interest that is relatively new. In this section, three examples are laid out of how CSO involvement in the policy process has resulted in more realistic and effective education services and an environment where CSOs are viewed as legitimate education planners and providers in a position to hold the state accountable for policy formulation and implementation.

\subsection{Sarva Shiksha Abhiyan}

Sarva Shiksha Abhiyan (SSA) means 'Universal Elementary Education Mission'. This national flagship programme was one of the largest collaborative efforts between the government and CSOs. Initiated in 2002 as a strategy for realising the Right to Education, the programme aims to provide universal elementary education for all children aged 6-14, by 2010 (MHRD 2006a). 
As a continuation of CSO mobilisation around the Right to Education, leading NGOs, academics and activists were invited to participate in the policyplanning process that led to the SSA. The government wanted to graft lessons learned from CSOs working on education, mostly in the context of motivated staff working in localised and concentrated experiments, to the larger policy framework. ${ }^{2}$ Concepts of micro-planning and decentralisation underpin the SSA. In the absence of defined habitation units small enough for microplanning, the concept of Kshetras - the catchment area of a municipal school - evolved in Delhi. ${ }^{2}$ Heads of primary and upper primary schools, in collaboration with other school officials, teachers, representatives of NGOs and members of Vidyaylaya Kalyan Samiti's (VKS) or School Welfare Committees, participated in developing Kshetras (NCT 2004).

Children who are not enrolled in formal schools are eligible for NGO-run Learning Centres in their geographical vicinity. The Learning Centres aim to mainstream children into government schools by improving their language and arithmetic skills. In 2001, 140 NGOs were allotted 1,500 Learning Centres. A demand for more Learning Centres in 2003, due to high numbers of out-of-school children in some Kshetras, led to 84 more NGOs joining the programme. By July 2004, out of the 90,174 children taught in the Learning Centres, 7,287 had been mainstreamed to government schools from Learning Centres run by NGOs (NCT 2004).

While government education departments are ultimately in charge of monitoring the programme and collecting NGO reports, the SSA monitoring formats were developed in participatory workshops and an on-site Kshetra Nodal Officer regularly monitors the programme (NCT 2004). Outside the SSA system, university students and volunteers from the NGO PRAVAH conduct unannounced checks at Learning Centres (NCT 2004).

The collaboration between government and NGOs improved the programme in terms of design and implementation. In terms of design, the microplanning of the SSA programme led to differentiation between varied categories of deprived children. Local NGOs used their first-hand knowledge of the communities in their Kshetras to identify the differences between, for example, the needs of a working child, street child, domestic help child and child of a migrant to design specialised education methods and curriculums. Specially designated funds have also been given to NGOs for opening Learning Centres for specific groups like working children, children of sex workers, girls and street children (NCT 2004).

In terms of implementation, SSA increased the capacity of NGOs to run the Learning Centres effectively. ${ }^{3}$ Government funding partly accounted for NGOs' increased capacity. But more importantly, NGOs were effective because they gained recognition as legitimate actors in the overall government programme for education. Schools became receptive to working with NGOs, whereas before SSA such collaboration had been difficult. SSA bridged the gap between citizens and government through collaboration at every level of policy formulation and implementation, from the budgeting to the education design. There are now joint government-NGO attempts to include School Welfare Committees, parents and NGOs in monitoring the Learning Centres.

There are, however, some areas of concern. For example, problems of duplicated student enrolment are rampant among NGOs, and there is yet a system devised to check and curtail this problem. Moreover, the quality of education in the Learning Centres varies from NGO to NGO. Though there is a selection process for the NGOs to run the Learning Centres, it is often the case that some NGOs are far better qualified and equipped to train students than others. Worryingly, some NGOs have a high rate of mainstreaming students into government schools whereas others have a much lower success rate.

Despite these problems, the collaborative process of planning, implementing and monitoring the Learning Centres indicates how CSOs and government can work in partnership. The design of the Learning Centres to address the specific needs of children from varying backgrounds validates the importance of including local civil society in the planning process to create realistic programmes. The status of legitimacy gained by NGOs enables them not only to effectively carry out the programme but also to be in a position to hold the government accountable for implementation.

\subsection{Preparing textbooks with the Delhi State Council for Educational Research and Training} The Delhi State Council for Education and Research Training (SCERT) case highlights the role of CSOs in 
facilitating the textbook design process and bringing about a qualitative change in textbooks for government and private schools.

SCERT Delhi was created as part of the education decentralisation process in the late 1980s to train teachers and improve the quality of schooling (Rajan 2006). In a successful collaboration with civil society, SCERT Delhi produced an elementary education textbook series. However, the design and adoption of the textbook series was far from straightforward.

The National Council for Educational Research and Training (NCERT), under the Hindu nationalist National Democratic Alliance government's support, had designed a national curriculum in 2000 with syllabi and textbooks. However, CSO activists protested against the curriculum for its non-secular leanings, bringing the case to the Indian Supreme Court. The Supreme Court sided with CSO activists and directed NCERT to revise the national curriculum. In the meantime, the Delhi state government, which was responsible for preparing and distributing textbooks to government-run schools, was dissatisfied with the new textbooks. When NCERT refused to let the Delhi government continue using old textbooks, the State decided that SCERT Delhi, the State counterpart of NCERT, should prepare a new set of textbooks (MHRD 2006b).

The pressure of preparing 50 textbooks in eight months was a difficult task but it was also an opportunity that led to the massive and successful collaboration between government school authorities and civil society (Rajan 2006).

Representatives from SCERT, government and private schools, university departments, research institutes, NGOs engaged in education and others from civil society produced textbooks with clear and relevant material targeted to children for whom Hindi is a second language.

This collaborative process was successful in two ways. First, it eased tensions between the government school administration and SCERT, which had taken a bold step to change the curriculum and contents of the books in the middle of the academic session. Second, academics involved in the process made the text more accessible to children with Hindi as a second language by using simple everyday words. This encouraged attendance of migrants' children, who often have difficulty with Hindi. The new books also used illustrations intended for children and focused on life in Delhi to make learning more relevant.

Despite these textual changes however, examination results have been poor. The delay in the production of the textbooks meant that teachers did not receive formal training on the new textbooks. In addition, there was no sustained civil society involvement after the textbooks were produced. This was partly due to the process involving a loosely organised collective coming together solely for the purpose of preparing the textbooks. Perhaps a more sustained involvement of academics and activists would have eased the process. Overall, the partnership between civil society and government in designing education materials shows how local knowledge can be incorporated into designs and how inclusion of civil society can facilitate a planning process.

\subsection{The Mid-Day Meal Scheme}

Using the case of the Mid-Day Meal Scheme, I trace the involvement of NGOs in holding the government accountable in initiating and directly implementing and monitoring the scheme. In order to increase the attendance, enrolment, retention, and nutritional status of $6-10$ year-old children, the Indian government set up the Nutritional Support to Primary Education (NSPE) in 1995, which mandated that all children in government schools and government-aided schools were provided with cooked meals (MHRD 2006c). Government schools in Delhi gave students uncooked food, such as biscuits and wafers. The dry ration scheme led to an increase in the student enrolment but not in class attendance or nutrition levels (De Noronha and Samson 2005).

CSO activists lobbied for cooked meals, taking the case to court in 2001. The Indian Supreme Court ruled on the case by directing all states to provide cooked mid-day meals (MCD 2005). Within two and a half years, all schools in Delhi provided cooked meals. The Municipal Corporation of Delhi (MCD), one of the local government elementary education service providers in Delhi, at first employed a number of private caterers to cook and deliver the meals but due to the costly profiteering and corruption of the caterers, the government made a decision to invite NGOs to the scheme and switch to using their services. ${ }^{2}$ Though it is too early to tell, NGO involvement appears to be more favourable and sustainable for the state (Patnaik 2006). The 
MCD began with 72 suppliers, which have since reduced down to $11 \mathrm{NGOs}$ running 13 kitchens and providing food for 945,000 children (MCD 2005). With the inclusion of $\mathrm{NGOs}$ and other service providers, each making their own infrastructural investments including land, building and machinery, the Delhi government set up the Mid-Day Meal Scheme with negligible costs (MCD 2005).

In order to monitor quality, a committee comprising of the head master, the teacher in charge of the Mid-Day Meal Scheme, a member of the Parent Teacher Association and a member of Resident Welfare Association or a Senior Citizen living in the vicinity, checks the food daily before serving it to the children. The Nutrition Foundation of India and the Sri Ram Industrial Research Institute are also involved in testing the food from kitchens and schools (MCD 2005).

There have been some difficulties with the scheme. Subcontracting to private providers has created problems of insufficient quantities of food being served and children falling ill from the meals - the media reported 19 cases of food poisoning (De Noronha and Samson 2005). NGOs cite limited funds arriving too late and uncoordinated and constant over-monitoring by teachers as persistent problems.

Another problem is the disparity in the level of civil society activism between MCD and New Delhi Municipal Corporation (NDMC) schools. Most MCD schools are situated in slum areas, resulting in schools with a poor parent-teacher ratio and parents who often do not have the time to monitor their school's conditions. This is compared with NDMC schools whose students are primarily the children of the domestic servants of government officials, businessmen, professionals and other wealthy households. These families are more aware of their children's needs and rights in schools. ${ }^{4}$ There have been a greater number of individual cases of parents of NDMC schools lodging complaints about issues regarding shortage of notebooks, poor level of teaching and below standard mid-day meals than there have been in MCD schools. ${ }^{4}$ In addition to being situated in poorer areas, MCD schools are bureaucratic and internal politics prevents the organisation from working efficiently. This means that it is more difficult for parents to intervene in MCD schools, particularly when parents are poor and poorly informed. Civil society can use this situation as an opportunity to strengthen community participation and influence in education programmes in poorer areas.

This case study points to the fact that CSO involvement in all phases of the policy process, from advocating for the creation of new programmes to implementation and monitoring, results in better policies. NGOs effectively implemented the scheme because they had a long-term vested interest in the scheme's goals, on the whole providing honest costeffective services. CSOs play a central role in monitoring the scheme and can take advantage of an important opportunity to support and organise poor communities' participation in holding education service providers accountable in their areas.

\section{Conclusions}

Civil society's efforts have led, in different degrees, to the enhancement of the delivery of education services by increasing the number of children in school and making school programmes more inclusive. The three case studies outlined illustrate how civil society's active participation in policy formation positively affects the design, implementation, and monitoring of programmes and legitimises civil society's ability to hold the government accountable.

In the case of the Sarva Shiksha Abhiyan programme, civil society partnered with the government to design an inclusive education programme that brought children previously excluded from the education system into specially designed Learning Centres. As a result of this close collaboration in policy formulation, the programme design successfully targeted specific groups of children, such as street children, and realistically reflected the diversity of children in the school catchment areas. In addition, NGOs gained a more legitimate status through their active involvement in policy formation. NGOs were able to implement the programme effectively because of their new status as legitimate education providers.

Similarly, civil society collaborated with government to design SCERT textbooks. The involvement of civil society eased tensions between the SCERT administration and the government school administration. Likewise, the involvement of academics resulted in textbooks that were easier to understand with more relevant and appropriate content. 
CSOs played a pivotal role in the conception, implementation, and monitoring of the Mid-Day Meal Scheme. In a collaborative effort among CSOs, activists successfully used litigation to hold the Indian government accountable for its commitment to the right to universal education. The government responded by creating the Mid-Day Meal Scheme to include more children in the education system. Because of civil society's participation in the creation of the scheme, civil society had an embedded interest in the subsequent implementation. NGOs extended their involvement in the implementation of the scheme to become the primary producers and distributors of the meals. A civil society committee closely monitors the scheme's implementation. NGOs and parents have held the Delhi government accountable for implementation through a complaints process and initiating reform in response to media coverage of problems.

\section{Notes}

1 Interview with R.I. Sudarshan at the India Habitat Centre on 10 February 2006.

2 Interview with P. Mohanthy at the Ministry of Human Resources Development, New Delhi on 23 September 2006.

3 Interviews with S. Bhagat, A. Kapur and N. Mohammed at Ankur NGO, New Delhi,

\section{References}

De Noronha, A.C. and Samson, M. (2005) 'Towards Benefits from Delhi's Mid-day Meal Scheme', Collaborative Research and Dissemination, October Kantha, K.V. and Narain, D. (2005) 'Retrieval of Childhood on Urban Common Schools', in R. Banerji and S. Surianarain (eds), City Schools, City Children: Challenges in Universalisation of Elementary Education in Urban India, UNESCO: 61

Kaushik, A. (2005) 'Elementary Education in Urban Areas', in R. Banerji and S. Surianarain (eds), City Schools, City Children: Challenges in Universalisation of Elementary Education in Urban India, UNESCO: 22

Mehendale, Archana (2005) Right to Education and Constitutional Amendment: A Case of India, Project Report, Delhi: GDNet's Bridging Research and Policy Programme

Ministry of Human Resource Development (MHRD) (2006a) Elementary Education, www.edu.nic.in (accessed 10 October 2006)
While all the cases have acknowledged weaknesses with the programmes and schemes outlined, these weaknesses point to new ways that civil society can be involved in holding the government and other stakeholders accountable.

These three case studies demonstrate how civil society's active participation in policymaking, and consequent detailed knowledge of and investment in those policies, result in practical policies that reflect realities on the ground, effective policy implementation, monitoring, and embedded mechanisms of accountability. Through participation in policymaking, civil society has made a significant contribution to reforming the education sector in Delhi.
Vasant Valley School, New Delhi and Prayas NGO, New Delhi on 28 August 2006.

4 Interview with V. Khanna of Managing Trustee, Prathan NGO, at India International Centre, Delhi on 12 October 2007.

Ministry of Human Resource Development (MHRD) (2006b) Some Innovative Practices in States Related to Quality Improvement under SSA, Pamphlet: 32

Ministry of Human Resources Development (MHRD) (2006c) 'Mid-Day Meal Scheme', National Programme of Nutritional Support to Primary Education, 27 September, Delhi

Municipal Corporation of Delhi (MCD), HQ Education Department (2005) Note Regarding Mid-Day Meal Scheme, Pamphlet, Ministry of Human Resources and Development

Narain, D. (2005) 'Retrieval of Childhood in Urban Common Schools', in R. Banerji and S. Surianarain (eds), City Schools, City Children: Challenges in Universalisation of Elementary Education in Urban India, UNESCO: 21

National Capital Territory (NCT) (2007) State Annual Work Plan and Budget 2006-2007 1: 121

National Capital Territory (NCT) (2004) Vidyalaya Kalyan Samiti Handbook: 2, Delhi: NCT 
Patnaik, B. (2006) Right To Food Campaign: Integrated Child Development Services, www. righttofood.com (accessed 28 September 2007)

Rajan, J. (2006) Interview with 2002 Director of the Delhi State Counterpart of the National Council for Education and Training (SCERT) at India Habitat Centre, 2 September

Right to Food Campaign (2006) www.righttofood.com (accessed 23 September 2007)
Sinha, A. (2005) 'Universalising Quality Elementary Education: Challenges in Urban Areas', in R. Banerji and S. Surianarain (eds), City Schools, City Children: Challenges in Universalisation of Elementary Education in Urban India, UNESCO: 62 Tooley, J. and Dixon, P. (2005) 'Is There a Conflict Between Commercial Gain and Concern for the Poor? Evidence from Private Schools for the Poor in India and Nigeria', Economic Affairs 25.2: 20-6 